DOI: https://dx.doi.org/10.4314/sinet.v44i1.12

\title{
Abundance and diurnal activity patterns of hooded vulture (Necrosyrtes monachus Temminck,) in Addis Ababa abattoirs enterprise, Addis Ababa, Ethiopia
}

\author{
Mebrat Teklemariam and Bezawork Afework* \\ Addis Ababa University, College of Natural and Computational Sciences, PO Box 1176, Addis Ababa, \\ Ethiopia. E-mail: bezawork.afework@aau.edu.et
}

\begin{abstract}
Hooded vulture (Necrosyrtes monachus) is an African endemic scavenger listed as Critically Endangered species. The population is declining across its range and there is threat of significant decline in population and distribution in Ethiopia. Little efforts have been made to properly document the status of vulture population and their diurnal activity patterns in the country for ensuring long term conservation measures. A study was conducted in Addis Ababa Abattoirs enterprise, Ethiopia from November 2019 to January 2020 to investigate the abundance and diurnal activity patterns of hooded vultures. The abundance of these vultures was estimated by direct counts method at their feeding sites and scan sampling was employed to study the diurnal activity patterns of hooded vultures from dawn to dusk. Hooded vulture mean abundance was $216 \pm 40$ at the abattoir. Their diurnal activity pattern showed that they were observed feeding, resting (perching, watching and basking), preening, roosting and others activities such as walking, drinking, chasing and flying. They spent $37.73 \%$ of their time in resting followed by others (including walking, drinking, chasing and flying) $(27.73 \%)$. The major threat recorded for theses vultures in the abattoir includes shortage of food, human disturbances, negative attitudes and lack of awareness on the importance of the species. Further ecological studies and impacts of human activities on Addis Ababa Abattoirs enterprise should be conducted for the conservation of hooded vulture and other conspecifics in the area.
\end{abstract}

Key words/phrases: Abattoir, Conservation, Hooded vulture, Population size, Time budget,

\section{INTRODUCTION}

Hooded vulture is an, Old World vulture, African endemic that showed rapid decline across its range (Ogada and Buij, 2011; Ogada et al., 2016; Mullié et al., 2017) and it was up-listed to the status of Critically Endangered in 2015 on the IUCN Red List of Threatened Species (BLI, 2017). Its rapid decline has been caused by overhunting, persecution and indiscriminate poisoning, as well as improvements in slaughter house hygiene and rubbish disposal where the species previously fed (Ogada and Buij 2011; Odino et al., 2014).

Hooded vulture has two sub species namely; the Necrosyrtes monachus monachus which is smaller in size, very common and symbiotic with man and the Necrosyrtes monachus pileatus which is relatively larger in size, found away from humans but may scavenge off rubbish dumps in Africa (Mundy, 1985). These vultures have a relatively small size with bare pink face and throat with a narrow bill (Negro et al., 2006). The Juvenile are clearly recognizable from the adult based upon the dark brown feathers on the back of the head and lack of red facial pigmentation (Odino et al., 2014; Kibuule, 2016). Adults are more uniformly colored lacking the sharp upper wing contrast between browner coverts and darker regimes (Kibuule, 2016). Both sexes have the same appearance, the only difference being the relatively larger size of the female (Kushwaha, 2016).

Hooded vultures occupy a wide range of habitats including arid country, towns, grassland, cultivation and coastal areas (Mundy et al., 1992; Odino et al., 2014). They are highly conspicuous and can be found in any dumpsite and in large concentrations in slaughter houses (Henriques et al., 2018). In Ethiopia, Hooded vulture was the most abundant species in Addis Ababa Abattoirs Enterprise (Hiwot Hibste and Afework Bekele, 2007), local Vulture Restaurant (Getachew Mulualem et al., 2016) and waste disposal sites (Seyoum Kiros and Bezawork Afework, 2018). However, there is a fear of significant decrease in population and/or distribution of vultures in the country though there are still widespread and at least locally abundant species (Gedeon et al., 2017).

Soaring, feeding, appeasement displays, watching alert posture, flying, roosting, body care

${ }^{*}$ Author to whom correspondence should be addressed. 
and basking are among diurnal activity patterns of hooded vultures though the commonly observed activity is their feeding habit in dumping sites (Hiwot Hibste and Afework Bekele, 2007; Getachew Mulualem et al., 2016). The regular activity pattern of bird species is affected by physical factors such as disturbances and shortage of food (Getachew Mulualem et al., 2016).

Addis Ababa Abattoirs Enterprise is one of the vulture attractants that provides diverse niche including garbage dumps from slaughter house where various birds can find food and forest cover in the nearby areas that provide shelter and nesting sites. Considering the decline of vulture species, knowledge about the existing resource base and the required management conditions has to be well documented. In this regard, ecological requirements and population status of vultures is important so as to search possible conservation or management measures. The purpose of this study is to investigate the abundance of hooded vultures and their diurnal activity patterns in Addis Ababa Abattoirs Enterprise, Ethiopia.

\section{MATERIALS AND METHODS}

\section{Description of the Study Area}

Addis Ababa Abattoirs Enterprise (AAAE) is located in Addis Ababa; Kirkose sub-city, Kebele 05 . This abattoir covers an area of about $38,141 \mathrm{~m}^{2}$. Addis Ababa Abattoirs Enterprise is established by Addis Ababa City Administration, having objectives to provide Abattoirs service to the city in 1949 E.C. The boundaries of the study area are small public entrance to the North, Tenishua Akaki River to the West, Sarbet road to the South, and Mexico road to the East (Figure 1).The mean annual rainfall collected from the nearby Meteorological station is $1800 \mathrm{~mm}$ with a bimodal pattern and the mean average temperature is $18.5^{\circ} \mathrm{C}$ (Central Statistical Agency, 2015).

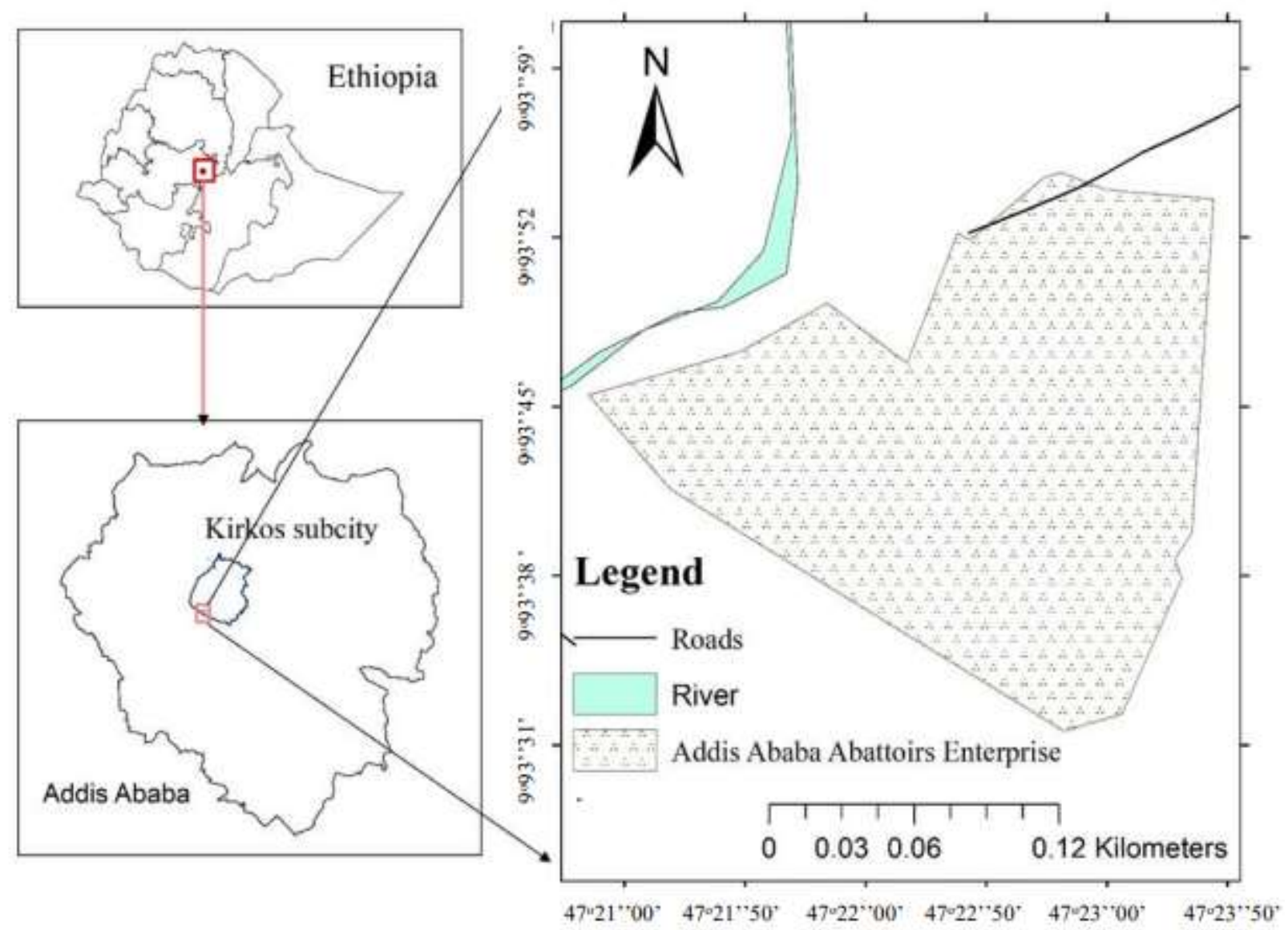

Figure 1. Location map of the study area. 


\section{Data Collection}

The study on the abundance and diurnal activity pattern of hooded vultures in Addis Ababa Abattoirs Enterprise was carried out from November, 2019 to January, 2020. Data was collected for three consecutive days per week for a total of 36 days. The abundance of hooded vultures in the enterprise was studied using a direct point count method following Pomeroy (1992). Two point count stations namely car washing and effluent discharging sites were used to collect data during morning (9:00- 11:00 AM) and late afternoon (3:30 - 4:30 PM) hours when birds are active in the site (Hiwot Hibste and Afework Bekele, 2007). Hooded vulture diurnal activity pattern surveys were conducted from dawn to dusk using scan sampling method (Roen and Yahner, 2005) and activities were recorded at every 10 minutes. In addition, an interview was made with the 25 of the 833 staff members of AAAE to understand their attitudes and perceptions towards vultures and vultures' conservation issue.

\section{Data Analysis}

The collected data were analyzed using excel, and presented in the form of tables and chart. The abundance was obtained by calculating the mean number of hooded vultures counted during the entire survey. Morning and evening counts were compared using paired $t$ - test. One-way ANOVA was used to assess the effect of fasting and nonfasting seasons on the abundance of this species. Age structure ratio was identified by computing proportion of immature to adults of hooded vultures. Percentage of diurnal activity patterns of the hooded vultures in the study area were analyzed by calculating the proportion of vultures engaged in each diurnal activity.

\section{RESULTS}

\section{Abundance of hooded vultures}

The mean abundance of hooded vultures was $216 \pm 40$ (range: 156 - 328). Statistically, there was no significant difference in the mean number of the species during morning and evening count $\left(t_{27}=\right.$ 1.552, $p=0.132$ ). The mean occurrence of the species during fasting $(238 \pm 37)$ and non-fasting $(194 \pm 30)$ seasons showed a significant difference $(F$ $1,29=11.139, p<0.005)($ Table 1$)$.

Table1. Abundance of hooded vulture in the study area.

\begin{tabular}{|c|c|c|c|c|c|c|c|c|}
\hline \multirow[b]{3}{*}{ Season } & \multicolumn{8}{|c|}{ Number of hood vultures } \\
\hline & \multicolumn{3}{|c|}{ Morning } & \multicolumn{3}{|c|}{ Evening } & \multicolumn{2}{|c|}{ Grand total } \\
\hline & Total & Range & Mean \pm SD & Total & Range & Mean \pm SD & Total & Mean \pm SD \\
\hline $\begin{array}{l}\text { Fasting } \\
(\mathrm{N}=14)\end{array}$ & 3373 & $185-328$ & $241 \pm 38$ & 3281 & $192-321$ & $234 \pm 35$ & 3327 & $238 \pm 37$ \\
\hline $\begin{array}{l}\text { Non- } \\
\text { fasting } \\
(\mathrm{N}=14)\end{array}$ & 2722 & $156-240$ & $194 \pm 32$ & 2708 & $141-231$ & $193 \pm 30$ & 2715 & $194 \pm 30$ \\
\hline $\begin{array}{l}\text { Total } \\
(\mathrm{N}=28)\end{array}$ & 6095 & $156-328$ & $218 \pm 42$ & 5989 & $141-321$ & $214 \pm 37$ & 6042 & $216 \pm 40$ \\
\hline
\end{tabular}

During the study period, adult and immature hooded vultures were identified and counted. The mean population size of immature $(113 \pm 22)$ was higher than adult $(103 \pm 29)$ hooded vultures. Their proportion was $52.1 \%$ immature to $47.9 \%$ adult vultures (Table 2).

Table 2. Age structure of hooded vulture in the study area.

\begin{tabular}{llll}
\hline \multirow{2}{*}{ Season } & \multicolumn{2}{l}{ Number of hooded vultures (mean \pm SD) } & Grand total \\
\cline { 2 - 3 } & Adult & Immature & $238 \pm 23$ \\
\hline Fasting $(\mathrm{N}=14)$ & $122 \pm 21$ & $116 \pm 26$ & $194 \pm 20$ \\
Non-fasting $(\mathrm{N}=14)$ & $85 \pm 22$ & $109 \pm 18$ & $216 \pm 26$ \\
\hline Total $(\mathrm{N}=28)$ & $103 \pm 29$ & $113 \pm 22$ & \\
\hline
\end{tabular}




\section{Diurnal Activity patterns of Hooded Vultures}

The diurnal activities of hooded vultures recorded during the study period were feeding, resting (perching, watching and basking), preening, roosting and others (including walking, drinking, chasing and flying) (Figure 2). Most of the hooded vultures (37.73\%) spent their day time activity on resting almost throughout the day followed by preening (15.35\%) The vultures perched on the roofs, branches of trees, pylons, top of buildings and cars, and nearby structures during resting. About $14.03 \%$ of vultures were engaged in feeding activities mainly between 9:0010:30 AM. Roosting (5.16\%) in hooded vultures was observed during 4:00-6:20 PM having a peak time between 5:00-6:20 PM. Other activities that include flying, basking and chasing constituted $27.73 \%$ of their activity.

Direct observation and interview with staff members of the abattoir revealed that the threatening factors of hooded vultures were shortage of food, human disturbance from inside and outside of the abattoirs. Additionally, capturing for traditional belief purpose, lack of awareness on the importance of the birds by the workers of the enterprise and electrocution are other threatening factors for hooded vultures in the study area.

\section{DISCUSSION}

Hooded vultures are the only vulture species found in the study area and utilized the area as a food source and fulfill their habitat requirement (feeding, perching and roosting sites). The population size of this species was much lower than the study conducted 12 years ago, where 800 individuals were recorded in the study area (Hiwot Hibste and Afework Bekele, 2007). This reduction may be due to the reduction in the discarded offal and scrap availability as the offal and scraps are now processed for production of fertilizers and pet food as has been reported in other African countries (Ogada and Buij, 2011). During the study period, the maximum numbers of hooded vultures was counted during the Orthodox Christian fasting period (24/11/19$06 / 01 / 20$ ) and the minimum number was recorded during the first two weeks after the end of the fasting period; a time when Christmas and Epiphany holidays were celebrated in Ethiopia. The main reason may be is that, during holydays people have traditional culture to slaughter animals around their houses and leftovers are disposed everywhere in the city's sewage channels and garbage dump sites. These leftovers are the source of food for most hooded vultures and hence lowest population was recorded in the abattoir. This result is supported by the report of Gbogbo and Awotwe-Pratt (2008) who reported that hooded vultures migrate to readily available dumped food sources. Dermody et al. (2011) also noted that the fluctuation in the vulture population in an area is due to changes in food availability.

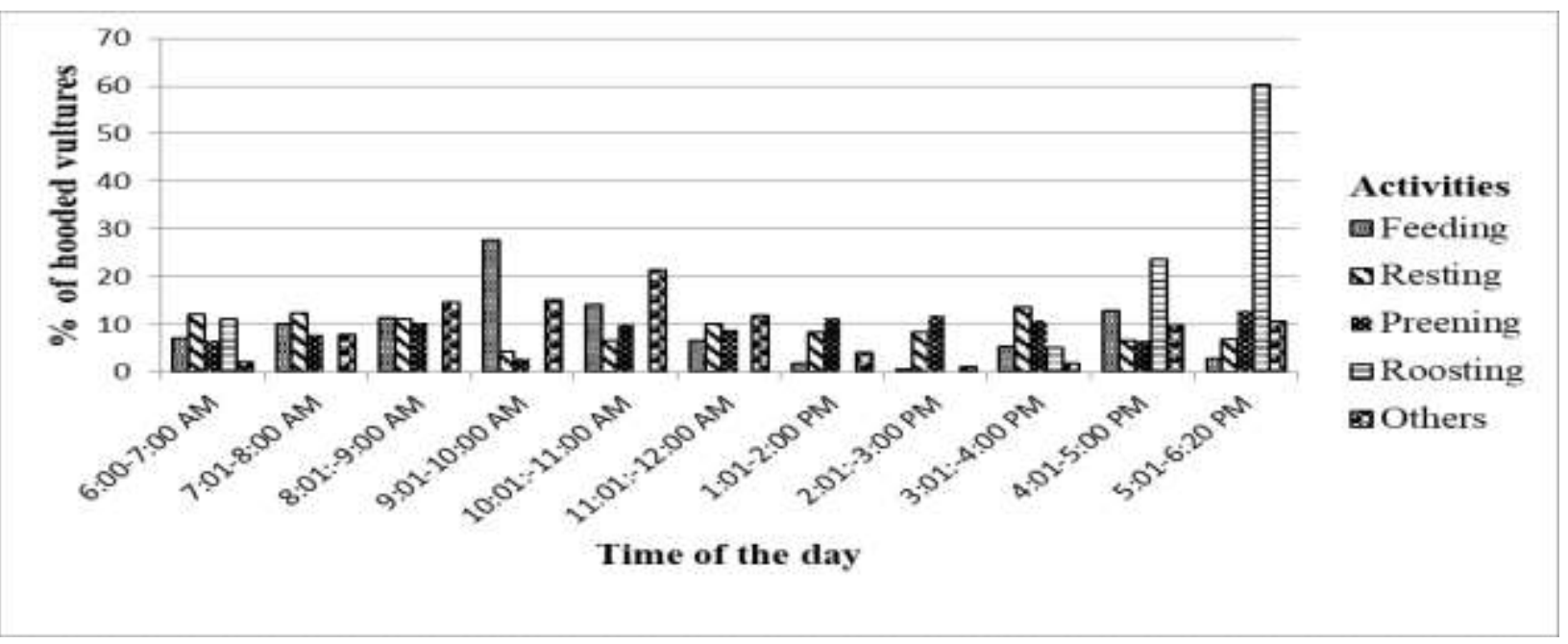

Figure 2 . Diurnal activity patterns of hooded vultures. 
The age structure of the observed hooded vultures showed high proportion of immature than adults. This may be due to the area being mostly utilized by non-breeding individuals as a feeding site than their breeding conspecifics. Brown et al. (1982) described that less records of adults than immature is recorded and this might be breeding adults concentrate their activities around nesting sites rather than ranging over larger distances. This is consistent with the suggestions of Mundy et al. (1992), Kibuule (2016) and Thompson et al. (2020) immature hooded vultures have larger home-ranges in seeking foraging areas away from adult conspecifics than adults which stay close to their nests during the breeding season.

Hooded vultures spent much of their time on resting followed by other activities such as walking, drinking, chasing and flying. Majority were observed resting throughout the day. This was similar with the observations of Hiwot Hibste and Afework Bekele (2007) and Getachew Mulualem et al. (2016). Hooded vultures were observed making numerous short flights between the dumping and perching or roosting sites until the abattoir workers and trucks in car washing site leave the area. They were observed perching on the roofs and nearby structures, or on the ground until the workers leave the area. Birds are sometimes forced to change their normal activity patterns due to human interference as was reported by Hiwot Hibste and Afework Bekele (2007), Getachew Mulualem et al. (2016), and Seyoum Kiros and Bezawork Afework (2018). Threat and appeasement display were also observed within hooded vultures and between hooded vultures and Marabou stork on feeding and roosting sites.

There was a considerable shortage of food in the abattoir since the formerly dumped byproducts of the slaughtered animals are processed and converted to different valuable products. This is in line with improved hygiene and proper management of abattoir refuse that reduce the availability of food for hooded vultures (Kibuule, 2016; Mullié, et al., 2017). The high records of hooded vultures during Orthodox Christian fasting period were due to the relatively significant food availability in the abattoir compared to the other areas of the city, since traditional slaughtering of animals was not practiced this fastening period. The variation in number of slaughtered animals in the abattoir might have also affected the offal availability for hooded vultures, as it changes the type and number of left overs available for hooded vultures and other scavenging birds such as marabou stork (Leptoptilos crumenifer), pied crow (Corvus albus) and black kite (Milvus migrans).

Discussion with the staff members of the abattoir revealed that they did not know the ecosystem roles of hooded vultures. However, they reported the considerable decrease in the species population size and also other different vulture species that were frequently observed in the study area. They have also a negative attitude towards hooded vultures and perceiving the species as unclean birds. Public negative attitudes and ignorance of the importance of hooded vultures threaten this species and other vulture species (Odino et al., 2014) and immediate conservation measures are required to save the remaining vultures.

\section{CONCLUSION}

The present study revealed that Addis Ababa Abattoir Enterprise supports a considerable number of hooded vultures which are the only vulture species remained in the area. Fluctuations in the abundance of hooded vultures were observed depending on the availability of food scraps in the abattoir. Hooded vultures and other scavenging birds have limited access to scraps and offal from the abattoir since the enterprise used all by-products of the slaughtered animals from direct selling of the scraps to different organization for converting the left overs in to different products resulting in a decline in the type and number of species in the area. Hooded vultures' population has also declined in the area indicating the need for immediate conservation action. Feeding, resting (perching, watching and basking), preening, roosting and others (including walking, drinking, chasing and flying) were the different diurnal activities of hooded vultures recorded throughout the study period, where they spent much of their time on resting followed by others (including walking, drinking, chasing and flying). 


\section{ACKNOWLEDGMENTS}

We thank Wolkite University, Department of Wildlife and Ecotourism Management for providing research materials to carry out this research. The sharing of information on hooded vultures and provision of relevant data from the staff and community of Addis Ababa Abattoirs Enterprise is appreciated.

\section{REFERENCES}

1. Birdlife International (2017). Necrosyrtes monachus. The IUCN Red List of Threatened Species 2017: e. T22695185A118599398. Accessed on 07/01/2021.

2. Brown, L., Urban, K. and Newman, P. (1982). Birds of Africa. New York: Academic Press. 521 Pp.

3. Central Statistical Agency of Ethiopia (CSA). Agricultural Sample Survey from 2004/052015/16. Farm management practices. Accessed from: www.csa.gov.et. Dermody, B. J., Tanner C. J. and Jackson, A. L. (2011). The evolutionary pathway to obligate scavenging in Gyps vultures. PLoS One 6: 1-6.

4. Gbogbo, F. and Awotwe, V. (2008). Waste management and hooded vultures on the legon campus of the University of Ghana in Accra, Ghana, West Africa. Vulture News 58:16-22.

5. Gedeon Kai, Zewdie Chemere and Töpfer T. (2017). The birds (Aves) of Oromia, Ethiopia- an annotated checklist. European Journal of Taxonomy 306: 1-69.

6. Getachew Mulualem, Shimles Ayalew and Weldemariam Tesfahunage (2016). Abundance and activity pattern of avifauna in Ashewa local vulture restaurant, DireDawa, Eastern Ethiopia. International Journal of Avian and Wildlife Biology 1(1):25-28.

7. Henriques, M., Granadeiro, J., Monteiro, H., Nuno, A., Lecoq, M, Cardoso, P., Regalla, A. and Catry, P. (2018). Not in wilderness: African vulture strongholds remain in areas with high human density. Plos One 13:1-21.

8. Hiwot Hibste and Afework Bekele (2007). Species composition, abundance and activity pattern of birds in Addis Ababa Abattoirs Enterprise area. Ethiopian Journal of Biological Sciences 6: 147-158.

9. Kibuule, M. (2016). Population Status of the Critically Endangered Hooded Vulture Necrosyrtesmonachus in Uganda's major urban centers. A project funded by the African Bird Club, Makerere University Uganda, Uganda. 36 Pp.

10. Kushwaha, S. (2016). Vultures in the Cultures of the World. Indian Biodiversity Conservation Society 1: 34-40.

11. Mullié, W., Couzi, F., Diop, M., Piot, B., Peters, T., Reynaud, P.and Thiollay, J. (2017). The decline of an urban hooded vulture Necrosyrtes monachus population in Dakar, Senegal, over 50 years. Ostrich 88: 131-138.

12. Mundy, P. J. (1985). The Biology of vultures: A summary of the Workshop Proceedings. ICBP Technical Publication 5:457-482.

13. Mundy, P., Butchart, D., Ledger, J. and Piper, S. (1992). The vultures of Africa. Russel Friedman and Acorn Books, Johannesburg. $464 \mathrm{Pp}$.

14. Odino, M., Imboma, T. and Ogad, D. (2014). Assessment of the occurrence and threats to hooded vultures Necrosyrtes monachus in western Kenyan towns. Vulture News 67:3-20.

15. Ogada, D. and Buij, R. (2011). Large declines of the hooded vulture Necrosyrtes monachus across its African range. Ostrich 82: 101-113.

16. Ogada, D., Shaw, P., Beyers, R., Buij, R., Murn, C., Thiollay, J. and Sinclair, A. (2016). Another continental vulture crisis: Africa's vultures collapsing toward extinction. Conservation Letters 9: 89-97.

17. Pomeroy, D. (1992). Counting Birds: A Guide to Assessing Numbers, Biomass and Diversity of Afro- Tropical Birds. African Wildlife Foundation, Nairobi.

18. Roen, K. and Yahner R. (2005). Behavioral Responses of Avian Scavengers in Different Habitats Northeastern Naturalist 12: 103-112.

19. Seyoum Kiros and Bezawork Afework (2018). Assessment of bird diversity and abundance from waste disposal sites in and around Gubre Subcity, Wolkite Town, Southwestern Ethiopia. International Journal of Waste Resources 8:1-7.

20. Thompson, L., Barber, D., Bechard, M., Botha, A., Wolter, K., \& Neser, W. et al. (2020). Variation in monthly sizes of home-ranges of hooded vultures Necrosyrtes monachus in western, eastern and southern Africa. Ibis. https://doi.org/ 10.1111/ibi.12836 